\title{
Three-dimensional structure of wind turbine wakes as measured by scanning lidar
}

\author{
Nicola Bodini ${ }^{1,2}$, Dino Zardi ${ }^{2}$, and Julie K. Lundquist ${ }^{1,3}$ \\ ${ }^{1}$ Department of Atmospheric and Oceanic Sciences, University of Colorado Boulder, Boulder, Colorado, USA \\ ${ }^{2}$ Department of Civil, Environmental and Mechanical Engineering, University of Trento, Trento, Italy \\ ${ }^{3}$ National Renewable Energy Laboratory, Golden, Colorado, USA
}

Correspondence to: Nicola Bodini (nicola.bodini@ colorado.edu)

Received: 29 March 2017 - Discussion started: 10 April 2017

Revised: 11 July 2017 - Accepted: 14 July 2017 - Published: 14 August 2017

\begin{abstract}
The lower wind speeds and increased turbulence that are characteristic of turbine wakes have considerable consequences on large wind farms: turbines located downwind generate less power and experience increased turbulent loads. The structures of wakes and their downwind impacts are sensitive to wind speed and atmospheric variability. Wake characterization can provide important insights for turbine layout optimization in view of decreasing the cost of wind energy. The CWEX-13 field campaign, which took place between June and September 2013 in a wind farm in Iowa, was designed to explore the interaction of multiple wakes in a range of atmospheric stability conditions. Based on lidar wind measurements, we extend, present, and apply a quantitative algorithm to assess wake parameters such as the velocity deficits, the size of the wake boundaries, and the location of the wake centerlines. We focus on wakes from a row of four turbines at the leading edge of the wind farm to explore variations between wakes from the edge of the row (outer wakes) and those from turbines in the center of the row (inner wakes). Using multiple horizontal scans at different elevations, a three-dimensional structure of wakes from the row of turbines can be created. Wakes erode very quickly during unstable conditions and can in fact be detected primarily in stable conditions in the conditions measured here. During stable conditions, important differences emerge between the wakes of inner turbines and the wakes of outer turbines. Further, the strong wind veer associated with stable conditions results in a stretching of the wake structures, and this stretching manifests differently for inner and outer wakes. These insights can be incorporated into low-order wake models for wind farm layout optimization or for wind power forecasting.
\end{abstract}

\section{Introduction}

A wind turbine wake is the volume downwind of a wind turbine, affected by the fact that the wind turbine removes momentum from the flow, thus reducing the downwind speed. Also, in the wake, the flow is more turbulent than in the inflow because of the rotation of turbine blades and the presence of the wind turbine itself as an obstacle to the incoming wind flow (Landberg, 2015).

Wind turbine wakes impact the layout optimization and energy production of large wind farms (Brower, 2012). In fact, the reduced wind speed in the wake region has a direct effect on the power extracted by downwind turbines (Neustadter and Spera, 1985; Barthelmie et al., 2010; Nygaard, 2014). Moreover, the increased turbulence in wakes enhances turbulent loads for downwind turbines, possibly inducing premature failure (Crespo et al., 1999; Sathe et al., 2013).

Therefore, wakes need to be studied and understood in order to maximize the efficiency of wind energy production. In particular, wake models are applied in several steps of the design and lifetime management of wind farms, whose layout is studied in detail to maximize the amount of energy generated by the turbines (Elkinton et al., 2006; Samorani, 2013). Moreover, the overall wind resource assessment process needs to take into account the effect of wakes to have a reliable prediction of future power production (Brower, 2012; Clifton et al., 2016). Lastly, wind farm control techniques incorporate detailed studies of wake characteristics while periodically changing some features of the turbines (such as yaw angle and pitch angle) in order to maximize the overall power production from the whole 
wind farm (Fleming et al., 2014, 2016; Gebraad et al., 2016; Vollmer et al., 2016). Typically, all these processes are computationally intensive and apply low-order models of turbine wakes (Elkinton et al., 2006; Chowdhury et al., 2012), such as the Jensen model (Jensen, 1983; Katic et al., 1986). In this way, several scenarios can be tested, but these lower-cost models oversimplify reality and may not be capable to fully represent wake characteristics in a detailed and realistic way (Barthelmie et al., 2006; Andersen et al., 2014).

Atmospheric stability has been shown to have a major impact on wind turbine wake evolution and wind farm performance in both observational (Magnusson and Smedman, 1994; Hansen et al., 2012; Wharton and Lundquist, 2012; Vanderwende and Lundquist, 2012; Barthelmie et al., 2013; Dörenkämper et al., 2015; Machefaux et al., 2015; Mirocha et al., 2015) and modeling studies (Churchfield et al., 2012; Aitken et al., 2014b; Mirocha et al., 2014; Machefaux et al., 2015; Abkar and Porté-Agel, 2015; Abkar et al., 2015): wakes in stable conditions persist for long distances downwind, while during unstable conditions the enhanced turbulent mixing erodes the wakes more quickly.

Wake characterization from field data can validate and improve the quality of numerical models. Data from field campaigns avoid possible limitations of wind tunnel simulations, such as down-scaled geometric dimensions and low Reynolds numbers (Iungo et al., 2013). Lidars and radars have been widely used recently to characterize wind turbine wakes. These instruments can measure wind characteristics above the heights of most traditional meteorological towers, and they can be deployed and moved rather easily, allowing measurements at several different locations. Many wake validation studies from remote sensing measurements focus on individual isolated turbines (Käsler et al., 2010; Bingöl et al., 2010; Trujillo et al., 2011; Hirth et al., 2012; Hirth and Schroeder, 2013; Aitken et al., 2014a; Aitken and Lundquist, 2014; Bastine et al., 2015; Kumer et al., 2015), with some studies that aim to reconstruct the three-dimensional structure of wind turbine wakes (Iungo et al., 2013; Banta et al., 2015). The interactions between multiple wakes must be captured in studies of large wind farms, as done by Clive et al. (2011), Hirth et al. (2015a, b), Kumer et al. (2015), Wang and Barthelmie (2015), Aubrun et al. (2016), and van Dooren et al. (2016).

In this paper, we analyze scanning lidar and profiling lidar measurements from the CWEX-13 field campaign in a large wind farm in Iowa, and we extend the individual wake detection algorithm proposed by Aitken et al. (2014a) to characterize multiple wakes. The three-dimensional structure of wakes from a row of four turbines is assessed in terms of velocity deficit, width of the wakes, and wake centerlines. Section 2 describes the CWEX-13 field campaign and how we use measurements from the instruments deployed at the site. In Sect. 3 we present the wake characterization algorithm for multiple wakes, an expansion of the algorithm proposed by Aitken et al. (2014a). Section 4 highlights how wake char- acteristics (velocity deficit, wake width, and wake centerline) change in three-dimensional space, and for the first time we quantify the effect of ambient wind veer on the vertical stretching of the structure of wakes. In Sect. 5 we compare the present results with those obtained in previous studies, and we suggest possible future work to improve wake simulations and models.

\section{Data and methods}

This study analyzes the scanning lidar and profiling lidar measurements from the CWEX-13 observational campaign, summarized in Takle et al. (2014) and Vanderwende et al. (2015).

\subsection{CWEX-13 observational dataset}

CWEX-13 campaign (Lundquist et al., 2014) took place between late June and early September 2013 in a wind farm in central Iowa, the same wind farm studied in previous CWEX campaigns; however, CWEX-13 focused on a part of the wind farm that is different from what is discussed in Rajewski et al. (2013), Rhodes and Lundquist (2013), Mirocha et al. (2015), and Lee and Lundquist (2017). The region exhibits strong diurnal cycles of atmospheric stability and frequent nocturnal low-level jets (Vanderwende et al., 2015). The area has a flat topography, with large fields of corn (height 1-2 m) and soybeans (height $0.3-0.8 \mathrm{~m}$ ). The region also has four small villages, some riparian regions and a few trees and buildings (some photos of the site are included in the Supplement).

Figure 1 shows a schematic diagram of the area of the wind farm of interest in CWEX-13. The yellow dots represent the wind turbines, whose main technical specifications are reported in Table 1.

For the purpose of this work, we focus on the characterization, using scanning lidar data, of the wakes from the row of four turbines enclosed in the purple ellipse in Fig. 1.

\subsubsection{Lidar measurements}

Three WINDCUBE v1 vertical profiling lidars (blue diamonds in Fig. 1) were deployed at the site during the field campaign, and they were located south of the studied row of four turbines, $8.5 \mathrm{D}$ north of the above-mentioned turbines, and $5.7 \mathrm{D}$ north of a second row of turbines. These instruments provided vertical profiles of wind speed and direction from 40 to $220 \mathrm{~m}$ above the surface, with measurements collected every $20 \mathrm{~m}$. At CWEX-13, southerly wind conditions dominated the campaign. So, we used data from the WC-1 profiling lidar to measure upwind conditions for the studied row of turbines, and calculate the ambient wind veer.

From 31 July to 6 September 2013, a LEOSPHERE WINDCUBE 200S scanning lidar was deployed with the northernmost WINDCUBE v1 profiling lidar (WC-3 in 


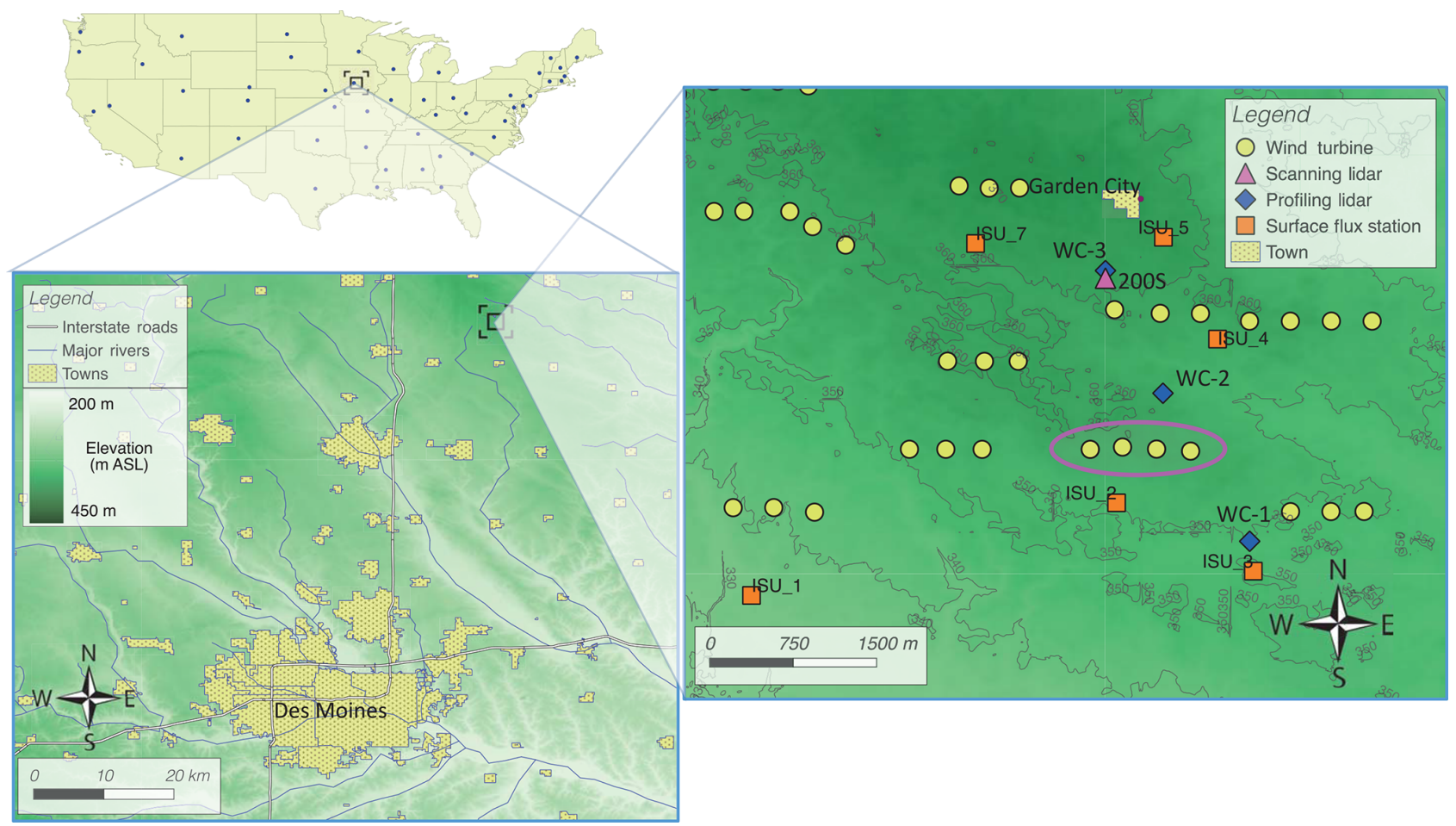

Figure 1. Schematic view of the part of the wind farm in central Iowa where the CWEX-13 field campaign took place. The row of four turbines whose wakes are detected by the scanning lidar is highlighted in a purple ellipse.

Table 1. Technical specifications of the studied wind turbines in CWEX-13 field campaign.

\begin{tabular}{lr}
\hline Rotor diameter $(D)$ & $80 \mathrm{~m}$ \\
Hub height & $80 \mathrm{~m}$ \\
Rated power & $1.5 \mathrm{MW}$ \\
Cut-in wind speed & $3.5 \mathrm{~m} \mathrm{~s}^{-1}$ \\
Rated power at & $11 \mathrm{~m} \mathrm{~s}^{-1}$ \\
Cut-out wind speed & $20 \mathrm{~m} \mathrm{~s}^{-1}$ \\
\hline
\end{tabular}

Fig. 1). Vanderwende et al. (2015) demonstrated good agreement between the co-located scanning and WC-3 profiling lidars measurements at the altitudes where measurements overlapped. Scanning lidars can operate sweeping the azimuth angle with a constant elevation angle, the so-called plan position indicator (PPI) mode (velocity azimuth display - VAD - mode when a full conical scan is conducted), or sweeping the elevation angle while holding the azimuth angle fixed, in the so-called range-height indicator (RHI), mode (Sathe and Mann, 2013). In CWEX-13, the scanning lidar used a combination of PPI, VAD and RHI scans, with a 30 min cycle (each PPI scan lasted approximately $100 \mathrm{~s}$, spanning an azimuth range of $50^{\circ}$ with a speed of $0.5^{\circ} \mathrm{s}-1$, while a RHI had a duration of about $30 \mathrm{~s}$; see Table 2).

Measurements were collected with slant range gates of $50 \mathrm{~m}$ at ranges up to $5000 \mathrm{~m}$ from the instrument, with an an- gular resolution of $0.5^{\circ}$. Line-of-sight (radial) velocity was measured with an accuracy better than $0.5 \mathrm{~m} \mathrm{~s}^{-1}$.

Given the dominant southerly wind conditions, the WINDCUBE 200S scanning lidar can use horizontal (PPI) scans to observe wakes propagating from the row of four turbines of interest. The horizontal scans were performed at six different elevation angles, giving a range of different vertical positions depending on the distance from the lidar. Approximately $10 \mathrm{~min}$ were required to collect the series of six elevation tilts; elevation angles varied from 1.5 to $2.8^{\circ}$, which allow measurements at a variety of vertical positions between the bottom and top of the rotor disk of the turbines, as shown in Fig. 2.

We select for a detailed analysis 2 days (23 and 26 August 2013) displaying wind conditions representative of the typical southerly wind pattern for the site. The first case, $23 \mathrm{Au}-$ gust, had predominant southeasterly wind conditions, with relatively low wind speed, which never exceeded $10 \mathrm{~m} \mathrm{~s}^{-1}$ at $220 \mathrm{~m}$ a.g.l. During 23 August 2013, 438 PPI scans were performed, 73 for each of the six elevation angles. In contrast, 26 August showed southwesterly wind, which is the most common situation for the site, with greater wind speed (up to $20 \mathrm{~m} \mathrm{~s}^{-1}$ at $220 \mathrm{~m}$ a.g.1.). During 26 August 2013, 576 PPI scans were performed, 96 for each elevation angle. By comparing the results from these two different days, the effect of wind direction on some wake characteristics can be assessed. Figure 3 shows examples of maps of line-of-sight ve- 
Table 2. Description of the 30 min cycle of scanning lidar scans in CWEX-13 field campaign. The characteristic fixed angle refers to the elevation angle for PPI and VAD scans and the azimuth angle for RHI scans.

\begin{tabular}{lllrl}
\hline $\begin{array}{l}\text { Number } \\
\text { of scans }\end{array}$ & $\begin{array}{l}\text { Type } \\
\text { of scan }\end{array}$ & Characteristic fixed angle & $\begin{array}{r}\text { Duration of } \\
\text { each scan }\end{array}$ & $\begin{array}{l}\text { Cumulative } \\
\text { time }\end{array}$ \\
\hline 2 & VAD & $75^{\circ}, 60^{\circ}$ & $132 \mathrm{~s}$ & $00: 00-04: 24$ \\
6 & PPI & $2.8^{\circ}, 2.5^{\circ}, 2.2^{\circ}, 2.1^{\circ}, 1.8^{\circ}, 1.5^{\circ}$ & $104 \mathrm{~s}$ & $04: 24-14: 48$ \\
3 & RHI & $160^{\circ}, 170^{\circ}, 180^{\circ}$ & $32 \mathrm{~s}$ & $14: 48-16: 24$ \\
6 & PPI & $2.8^{\circ}, 2.5^{\circ}, 2.2^{\circ}, 2.1^{\circ}, 1.8^{\circ}, 1.5^{\circ}$ & $104 \mathrm{~s}$ & $16: 24-26: 48$ \\
6 & RHI & $160^{\circ}, 170^{\circ}, 180^{\circ}, 180^{\circ}, 170^{\circ}, 160^{\circ}$ & $32 \mathrm{~s}$ & $26: 48-30: 00$ \\
\hline
\end{tabular}

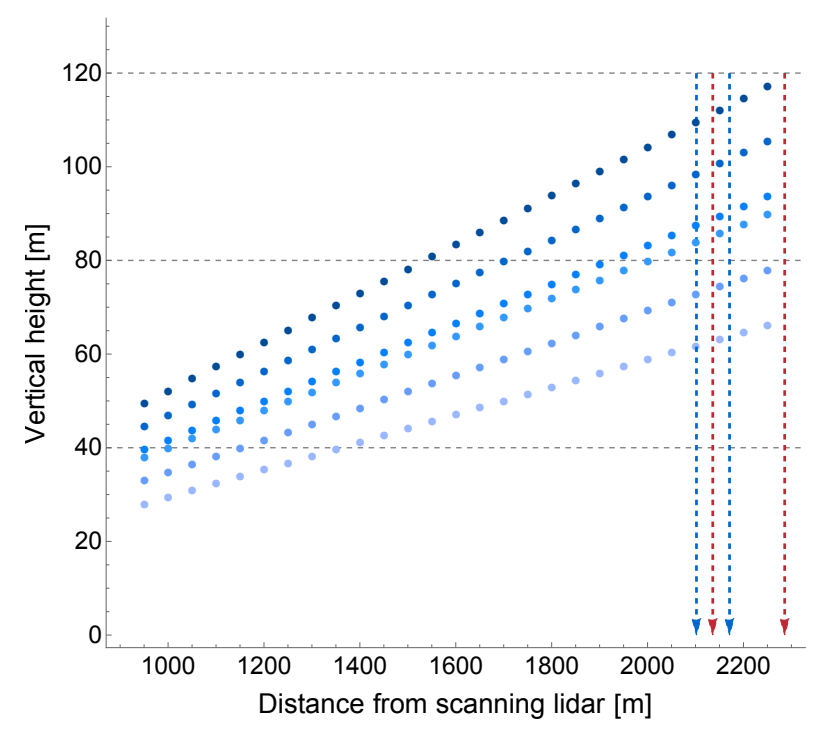

Figure 2. Schematic representation of the position where measurements from PPI scans are available, at six different elevation angles, as a function of the distance from the scanning lidar. The horizontal dashed lines show the vertical limits of the rotor disk of the turbines and hub height. The position of the four turbines is represented by the vertical dashed lines, with red lines for outer turbines and blue lines for inner turbines. From the westernmost to the easternmost turbine, the distances from the scanning lidar are 2136, 2102, 2171, and $2286 \mathrm{~m}$. The change in elevation between the turbine location and the lidar location $(7 \mathrm{~m})$ is taken into account.

locity measured by the scanning lidar during two PPI scans performed at night on the selected days. The wind turbine wakes can clearly be detected in terms of reduced wind speed downwind of the four wind turbines.

\subsubsection{Surface flux measurements for quantifying atmospheric stability}

Several surface flux stations (provided by Iowa State University) were deployed at the CWEX-13 site (orange squares in Fig. 1). We used measurements from the surface flux station ISU_3 to assess atmospheric stability conditions, with the calculation of Obukhov length $L$, defined as

$L=-\frac{\overline{\theta_{\mathrm{v}}} \cdot u_{*}^{3}}{k \cdot g \cdot \overline{w^{\prime} \theta_{\mathrm{v}}^{\prime}}}$,

where $\theta_{\mathrm{v}}$ is the virtual potential temperature $(\mathrm{K})$, calculated from the sonic anemometer virtual temperature data $T_{\mathrm{v}}$ and the measured pressure $p$ as $\theta_{\mathrm{v}}=T_{\mathrm{v}}\left(\frac{p_{0}}{p}\right)^{R / c_{p}}$, with $p_{0}=1000 \mathrm{hPa}$ and $R / c_{p} \approx 0.286 ; k=0.4$ is the von Kármán constant; $g=9.81 \mathrm{~m} \mathrm{~s}^{-2}$ is the acceleration due to gravity; $u_{*}=\left(\overline{u^{\prime} w^{\prime}}{ }^{2}+{\overline{v^{\prime} w^{\prime}}}^{2}\right)^{1 / 4}$ is the friction velocity $\left(\mathrm{m} \mathrm{s}^{-1}\right)$; and $\overline{w^{\prime} \theta_{\mathrm{v}}^{\prime}}$ is the kinematic sensible heat flux $\left(\mathrm{W} \mathrm{m}^{-2}\right)$.

Reynolds decomposition for turbulent flows is applied to separate the average and fluctuating parts of the relevant quantities. The average time period used to compute the Reynolds decomposition must be much longer than any turbulence timescale, but much shorter than the timescale for mean flow unsteadiness. For this purpose, it has been fixed to $30 \mathrm{~min}$, a typical time range used to compute turbulent averages for atmospheric boundary layer phenomena (De Franceschi and Zardi, 2003; De Franceschi et al., 2009; Babić et al., 2012).

As to atmospheric stability, we consider neutral atmosphere for $L \leq-500 \mathrm{~m}$ and $L>500 \mathrm{~m}$; unstable conditions for $-500 \mathrm{~m}<L \leq 0 \mathrm{~m}$; and stable conditions for $0 \mathrm{~m}<L \leq$ $500 \mathrm{~m}$ (Muñoz-Esparza et al., 2012).

\section{Wake characterization algorithm for multiple wakes}

The line-of-sight velocity $\left(u_{\mathrm{LOS}}\right)$ measured by the WINDCUBE 200S scanning lidar (Fig. 4) during the horizontal (PPI) scans can be analyzed to determine wake characteristics and how they evolve in space as the wakes propagate. Aitken et al. (2014a) proposed a wake detection algorithm and applied it to characterize the wake from a single turbine, later expanding it to treat nacelle-based lidar measurements (Aitken and Lundquist, 2014). Here we expand the same algorithm to characterize wakes from a row of four turbines.

\subsection{Data pre-processing}

First, a threshold is imposed to the carrier-to-noise ratio (CNR), which represents the strength of the backscattered 
(a)

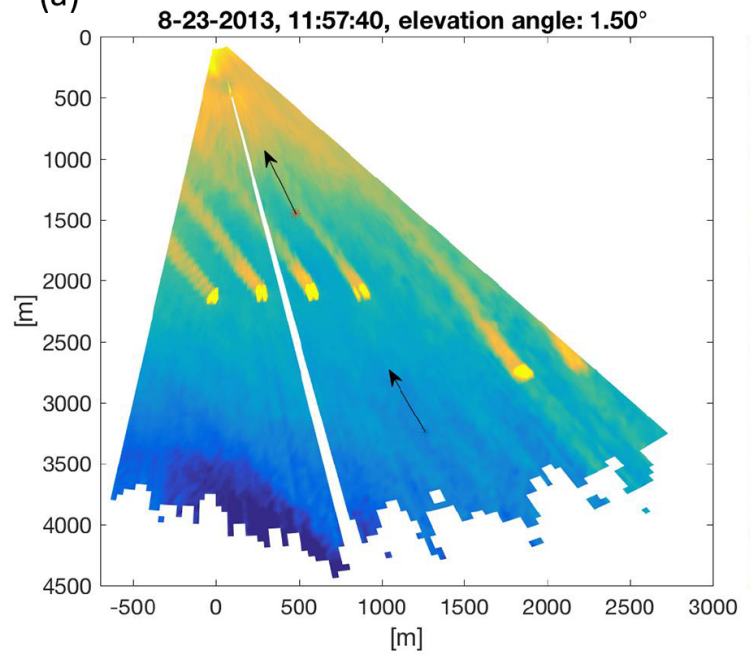

(b)

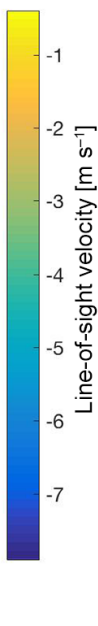

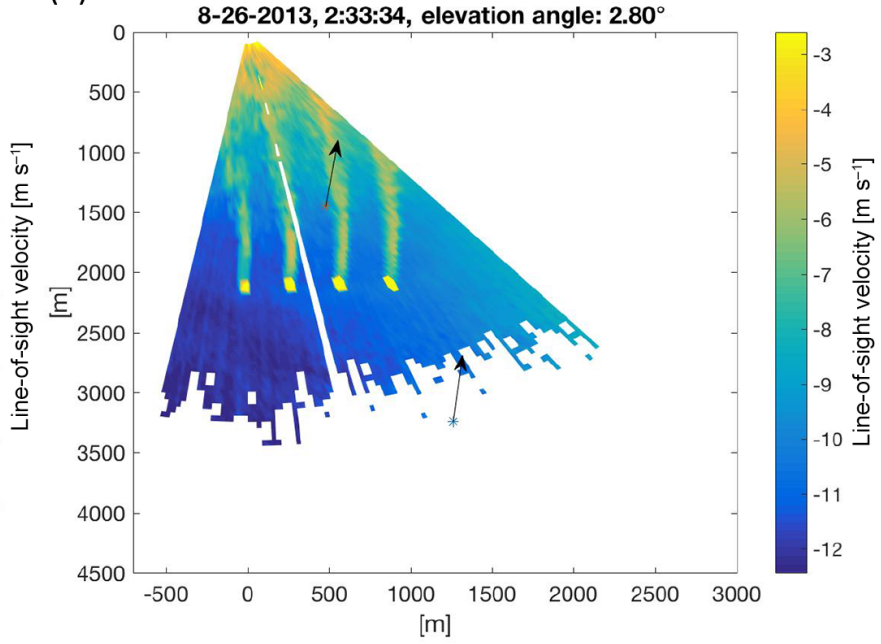

Figure 3. Color maps of line-of-sight velocity measured by the scanning lidar during two PPI scans performed at 11:57 UTC (06:57 LDT) on 23 August 2013 (a) and at 02:33 UTC (21:33 LDT) on 26 August 2013 (b). The scanning lidar is located in the origin of the coordinate system. The two arrows show wind direction as measured by the profiling lidars WC-1 and WC-2 at $80 \mathrm{~m}$ a.g.l.

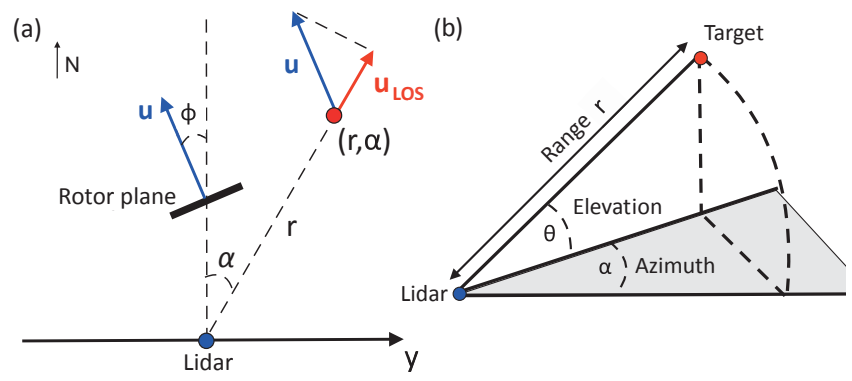

Figure 4. (a) Plan view of the coordinate system for scanning lidar PPI scans; (b) 3-D sketch of the main geometric quantities relevant in a lidar scan.

signal compared to background noise (values closer to $0 \mathrm{~dB}$ indicate a stronger signal relative to the noise): all measurements with carrier-to-noise ratio $<-27 \mathrm{~dB}$ are discarded from further analysis (Vanderwende et al., 2015). Measurements with a lower CNR often had unrealistically high $\left(>15 \mathrm{~m} \mathrm{~s}^{-1}\right.$ ) values of radial velocity; this threshold value is comparable with choices in other studies (Cariou et al., 2011; Bastine et al., 2015; Debnath et al., 2017). Moreover, in each scan, line-of-sight velocity data which are not included in the interval $(\mu-3 \hat{\sigma}, \mu+3 \hat{\sigma})$, where $\mu$ is the average of the data, are removed from the analysis. The standard deviation $\hat{\sigma}$ is evaluated according to the median absolute deviation (MAD), assuming normally distributed data: $\hat{\sigma}=1.4826 \mathrm{MAD}$, where $\mathrm{MAD}=$ median $\left(\mid u_{\mathrm{LOS}, i}-\right.$ median $\left.\left(u_{\mathrm{LOS}}\right) \mid\right)$. In the remaining part of the wake detection algorithm, measurements will be weighted according to the inverse of the square of the radial wind speed dispersion, which is a measurement of the standard deviation of the backscattered signal of the lidar and thus an indicator of the uncertainty of values (Vanderwende et al., 2015).

\subsection{Wake detection}

To implement the wake detection, measurements of line-ofsight velocity $u_{\mathrm{LOS}}$ at each range gate in each PPI scan are fitted to two different models: the first is for ambient flow conditions without wakes, the second represents each of the four wakes as a Gaussian function subtracted from uniform ambient flow (Tennekes and Lumley, 1972; Troldborg et al., 2007; Chamorro and Porté-Agel, 2009; Gaumond et al., 2014).

Ambient wind speed is modeled with uniform speed $u$ and direction $\phi$, as shown in Fig. 4. At a fixed elevation angle, the line-of-sight velocity $u_{\mathrm{LOS}}$ can be related to the assumed uniform ambient wind speed $u$ with a simple geometric transformation involving horizontal wind direction $\phi$ and the lidar azimuth angle $\alpha$, namely

$u_{\mathrm{LOS}}=u \cdot \cos (\alpha-\phi)$,

where both $\alpha$ and $\phi$ are $>0$ for clockwise rotations from north. The azimuth angle $\alpha$ can be related to the range gate $r$ and the transverse coordinate $y=r \cdot \cos (\theta) \cdot \sin (\alpha)$, yielding

$u_{\mathrm{LOS}}(y, r)=u \cdot\left(\frac{\sqrt{r^{2}-y^{2}}}{r} \cos \phi+\frac{y}{r} \sin \phi\right)$,

which represents the first model for $u_{\mathrm{LOS}}$ applied in the wake detection algorithm. In this case, the ambient flow wind speed $u$ and the ambient wind direction $\phi$ are the fitting parameters of the model. This "no wake" fit is the same as in Aitken et al. (2014a). 
The second implemented model represents each wake from the four turbines in the row as a Gaussian function (Tennekes and Lumley, 1972) subtracted from uniform ambient flow $u$ :

$$
\begin{aligned}
u_{\mathrm{LOS}}(y, r)= & \left\{u-\sum_{i=1}^{4} a_{i} \exp \left[-\frac{\left(y-y_{i}\right)^{2}}{2 s_{\mathrm{w} i}^{2}}\right]\right\} . \\
& \cdot\left(\frac{\sqrt{r^{2}-y^{2}}}{r} \cos \phi+\frac{y}{r} \sin \phi\right) .
\end{aligned}
$$

This second model has 14 fitting parameters: the ambient wind direction $(\phi)$, the ambient wind speed $(u)$, the amplitudes of the Gaussian functions $\left(a_{i}\right.$; i.e., the wake velocity deficit amplitudes), the four transverse coordinates of wake centers $\left(y_{i}\right)$, and four parameters controlling the widths of the wakes $\left(s_{\mathrm{w} i}\right)$. Note that each of the four wakes is modeled with its own parameters, permitting variable characteristics between the wakes. The amplitude $a_{i}$ can be 0 , for the trivial case of no wake.

Nonlinear regression (least squares) is applied with the two different models specified above. In the fitting procedure, the transverse coordinate $y$ is used as the independent variable, while the measured line-of-sight velocity $u_{\mathrm{LOS}}$ is the dependent variable; moreover, the dispersion of measured $u_{\mathrm{LOS}}$ is used as weights for the data. In setting the first-guess values for the parameters, physical limits are set: the velocity deficit amplitudes must be $\geq 0$ but lower than the uniform ambient flow wind speed $u$, the locations of the centers of the wakes must be included in the range of transverse coordinates $y$ in each scan, and the width of the wakes must be $>0$.

The best estimates for the parameters of the two models are found. An extra sum-of-squares $F$ test is applied to determine whether the second model, which is naturally suited to better fit data considering its higher number of parameters, is significantly better than first model in fitting the data. A threshold $p$ value is set to 0.05 ; if the calculated $p$ value is less than this threshold, then the second model is considered capable to significantly better represent the data, and thus it is selected (Kleinbaum et al., 2013).

Figure 5 shows an example of line-of-sight velocity measurements at a single range gate in a PPI scan (with error bars representing the dispersion of the measurements). The red continuous line is the fit performed by the wake characterization algorithm.

\subsection{Model acceptance criteria}

The quality controls implemented in the first steps of the wake detection algorithm (limits to CNR, MAD method to discard outliers, physical limits to the values of the fit parameters) assure a very good quality of the fits, measured in terms of Pearson correlation coefficient and mean squared error. However, some other quality-control steps are applied

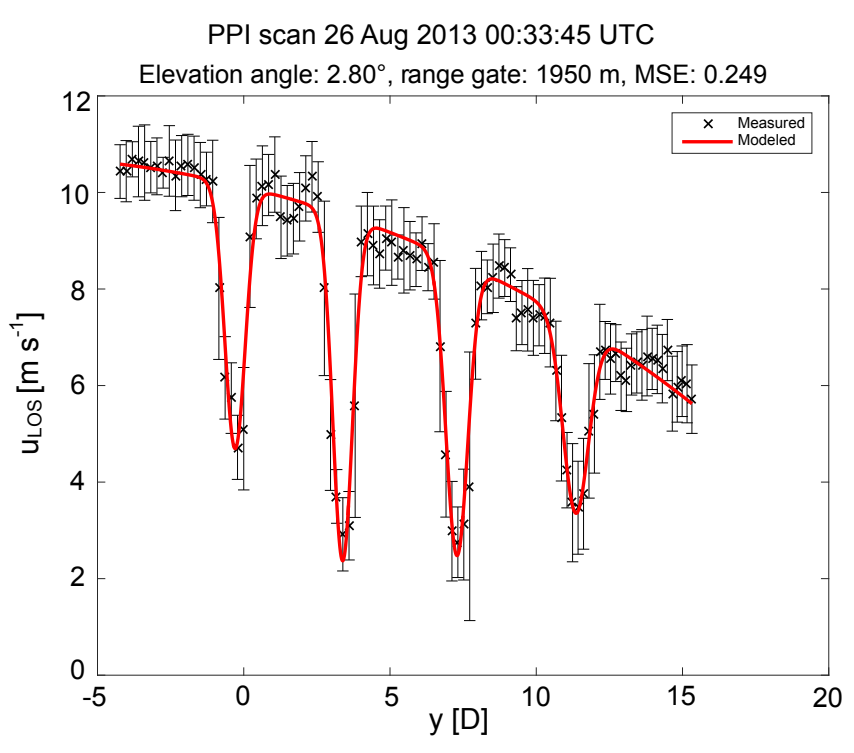

Figure 5. Example of line-of-sight velocity data measured by the scanning lidar at a specific range gate during a PPI scan. Error bars are the dispersion of line-of-sight velocity measurements. The red line represents the fit performed by the wake characterization algorithm.

to solve possible issues related with the complexity of the expansion of the algorithm to detect multiple wakes.

At the smallest range gates, depending on a given wind direction, not all the four wakes from the studied row of four turbines may be included in the lidar scan because of the limited range of azimuths of each scan. In these situations, the application of the second model, which aims to fit $u_{\text {LOS }}$ with four wakes, may result in the detection of some spurious wakes besides the actual (but less than four) real wakes seen in the PPI scan. These spurious wakes are typically detected where sudden - but very limited - natural changes in the lineof-sight velocity occur. To solve this false detection, fitted wakes with nonrealistic velocity deficits (smaller than half of the minimum velocity deficits of the other wakes detected at the same range gate) and/or widths (smaller than $0.1 D$ or bigger than one quarter of the whole transverse range) are excluded from the results.

Another issue is related to the possibility of the algorithm detecting wakes with a double-peaked shape - typical of near-wake (Magnusson, 1999) or arising from the interference of an obstacle with the laser beam of the lidar - as two separate wakes. The algorithm detects a double-peaked wake when the transverse positions of the centers of two adjacent wakes are closer than half of the width of the largest wake. When these double-peaked wakes are detected, the algorithm can instead consider a single-peaked wake with a velocity deficit amplitude which is the average of the two detected velocity deficit amplitudes, a wake center located at the average $y$ between the two detected peaks, and a wake width 
determined adding a half-width $\left(2 s_{\mathrm{w} i}\right)$ to each external edge of the two detected peaks.

Besides these quality-control steps, the algorithm can reorder the remaining wake parameters to associate them to the correct physical wake from the considered row of four turbines. This procedure is dependent on wind direction, which determines in which order the four wakes are excluded from the scan area of the lidar at lower range gates.

The wake characteristics database, which is the output of the application of the wake detection algorithm (which is publicly available at https://github.com/nicolabodini/ CWEX13), is then used to study how wake characteristics evolve in three-dimensional space.

For each detected wake, the velocity deficit is calculated as the ratio between the velocity deficit amplitude $a_{i}$ and the ambient flow wind speed $u$ (estimated from our algorithm at each performed fit at each range gate and elevation) (Vermeer et al., 2003):

$\mathrm{VD}_{i}=\frac{u-u_{\mathrm{wake}}}{u} \cdot 100=\frac{a_{i}}{u} \cdot 100$.

The wake width has been defined in different ways in the literature; here we calculate it as in Hansen et al. (2012):

$w_{i}=4 \cdot s_{\mathrm{w} i}$,

which is equivalent to the $95 \%$ confidence interval of the Gaussian velocity deficit profile.

The wake centerline will be studied considering the temporal evolution of the planar coordinates of the center of each wake, i.e., the peak of the velocity deficit.

As final quality-control steps, the MAD method is applied again to discard wake characteristics which do not lie within 3 standard deviations of the mean characteristic at each range gate for each whole night (Aitken et al., 2014a); moreover, only fits with Pearson correlation coefficient $\left(\operatorname{corr}\left(u_{\mathrm{LOS}}, \hat{u}_{\mathrm{LOS}} ; g\right)=\right.$ $\operatorname{cov}\left(u_{\mathrm{LOS}}, \hat{u}_{\mathrm{LOS}} ; g\right) / \sqrt{\operatorname{cov}\left(u_{\mathrm{LOS}}, u_{\mathrm{LOS}} ; g\right) \operatorname{cov}\left(\hat{u}_{\mathrm{LOS}}, \hat{u}_{\mathrm{LOS}} ; g\right)}$, where $g$ represents the data weights) larger than 0.9 and mean squared error $\left(\mathrm{MSE}=\frac{1}{\sum_{i=1}^{n} g_{i}} \sum_{i=1}^{n} g_{i}\left(\hat{u}_{\mathrm{LOS}, i}-u_{\mathrm{LOS}, i}\right)^{2}\right)$ lower than 0.5 are included in the final analysis of the results.

\section{Results}

Once all the fits are completed, and the wakes fully characterized, it is possible to study how the wake characteristics vary in space for the four studied turbines.

\subsection{Frequency of wake detection and atmospheric stability}

Atmospheric stability has a major impact (Churchfield et al., 2012; Iungo et al., 2013) on wind turbine wake evolution and wind farm performance: wakes in stable conditions persist

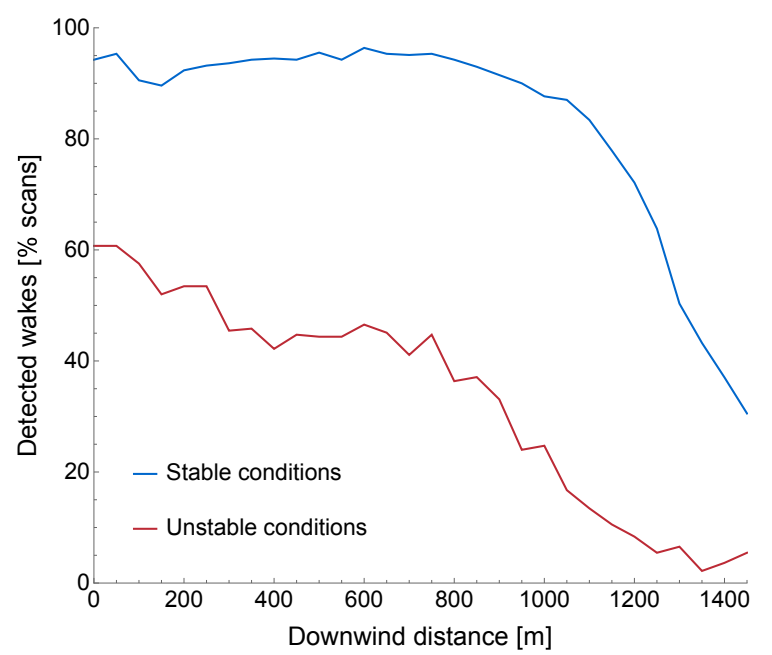

Figure 6. Percentage of wakes detected by the characterization algorithm vs. downwind distance, for stable and unstable conditions of the atmosphere (neutral conditions were detected only for very short periods and are not included here). Results from PPI scans performed on 23 and 26 August 2013.

for long distances downwind, while during unstable conditions the enhanced turbulent mixing erodes the wakes more quickly.

To get a quantitative measurement of this effect, Fig. 6 shows the percentage of scans where wakes were detected by the algorithm, at each range gate, for different stability conditions of the atmosphere (measured in terms of the Obukhov length) during all the 438 and 576 scans (at all the considered elevation angles) performed on 23 and 26 August 2013 , respectively. The plot clearly shows how wakes can easily be detected in stable conditions, while during unstable conditions the algorithm is not capable of properly detecting wakes at least $40 \%$ of the time. Moreover, wakes erode more quickly during unstable conditions, with the degradation becoming more intense approximately at $700 \mathrm{~m}$ $(\sim 8.5 D)$ downwind of the wind turbines, while under stable conditions wakes are detected in most of the scans up to approximately $1000 \mathrm{~m}(\sim 12 \mathrm{D})$ downwind of the turbines.

All the results presented in the next paragraphs focus on stable conditions of the atmosphere.

\subsection{Velocity deficit results}

Wind speed reduction in the wake region, measured in terms of velocity deficit, is the most distinct wake effect.

Figure 7 shows contour plots of velocity deficits for a wake from an outer turbine (panel a) and a wake from an inner turbine (panel b), computed using the results of the wake detection algorithm from PPI scans performed at six different elevation angles from 05:31 to 05:42 UTC (from 00:31 to 00:42 LDT) on 26 August 2013. The horizontal axis shows the downwind distance from the turbines, expressed in terms 
(a)

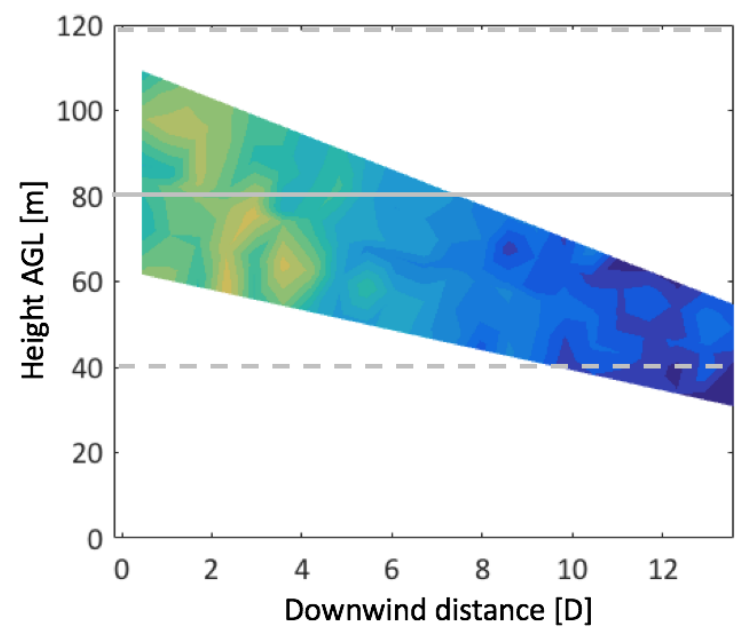

(b)

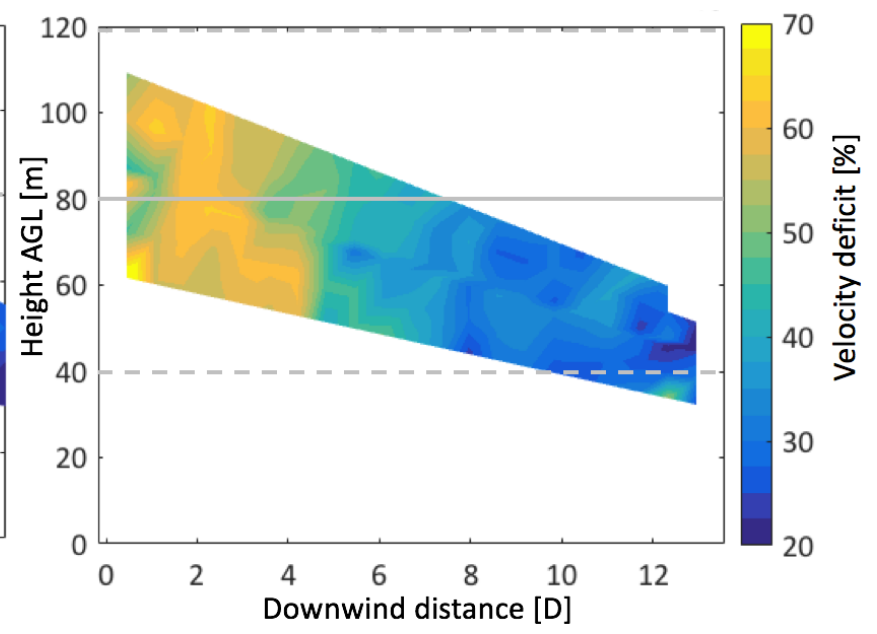

Figure 7. Velocity deficit vs. downwind distance, at different vertical positions, for wakes from (a) an outer turbine and (b) an inner turbine. Gray horizontal dashed lines represent the vertical limits of the rotor disk of the turbines; the horizontal continuous gray line shows the hub height of the turbines. Data collected from 05:31 to 05:42 UTC (from 00:31 to 00:42 LDT), 26 August 2013, from a succession of six PPI scans performed at six different elevation angles.

of rotor diameters $D$, with $D=80 \mathrm{~m}$. The plot clearly shows that the velocity deficit decreases with downwind distance, and the wake of the outer turbine exhibits smaller velocity deficits compared to the wake of the inner turbine.

To understand if the results are systematic, Fig. 8 shows velocity deficit versus downwind distance from the turbines, calculated from the 276 (242) PPI scans, at all the elevation angles, performed during the whole night - stable conditions - of 26 (23) August 2013. The continuous lines show the median values of velocity deficit, and the shaded area represents the standard deviation of the data.

As expected, velocity deficit decreases with downwind distance, since the speed reduction in the wake tends to become smaller due to the entrainment of free-stream surrounding air. The plot also confirms that wakes from outer turbines (number 1 and number 4 ) have lower velocity deficits than the wakes from inner turbines (number 2 and number 3 ) for relatively small downwind distances, with a difference up to $15 \%$. The presence of outer turbines seems to reduce the effectiveness of lateral entrainment of faster air to recover wind conditions in the inner wake regions of the wind farm. These results are comparable for both the considered nights: different wind directions do not seem to affect them.

\subsection{Wake width results}

The widths of the wakes also change with downwind distance (expressed in terms of rotor diameters $D$, Fig. 9).

Panel (a) shows results from the stable conditions of the night of 26 August 2013, while panel (b) shows results for the stable conditions of the night of 23 August 2013. In both cases, for all the four turbines, the wake widths increase mov- ing away from the turbine, exceeding $2 D$ after a downwind distance of $8-10 D$.

However, if we focus on the single wakes, we can see how different wind directions (southwesterly during 26 August, southeasterly during 23 August) can affect the ability of the scanning lidar to measure line-of-sight velocity and, thus, detect this characteristic of the wakes. By comparing the two plots in panels (a) and (b), it is clear that the scanning lidar systematically identifies as the widest the wake which, at a given downwind distance, is the most perpendicular to the laser beam (i.e., the last one the laser beam meets: turbine 4 , at the right edge of the row, for southwesterly wind; turbine 1, at the left edge of the row, for southeasterly wind). Then the detected width of the wakes progressively decreases moving to the wakes from adjacent turbines.

Figure 9c aggregates results from 23 and 26 August, and it shows how wake width changes with downwind distance considering the single turbines from the closest to the furthest from the scanning lidar, depending on the particular wind direction, as shown in the right schemes in the panel. The plot confirms the systematic dependence of the detected wake widths on the relative position between the wake and the scanning lidar.

This result is due to the relationship between the viewing angle and the aspect ratio of the lidar retrieval "pixels", which are related to the relatively long range gate $(50 \mathrm{~m})$ and relatively narrow azimuthal resolution $\left(0.5^{\circ}\right)$. As qualitatively shown in the schematic of Fig. 10, the scanning lidar measures the line-of-sight velocity in narrow pencilshaped "pixels". With this geometry, if the wind direction - and thus the wake - is aligned with the line of sight from the lidar, the wake width can be assessed with high precision 


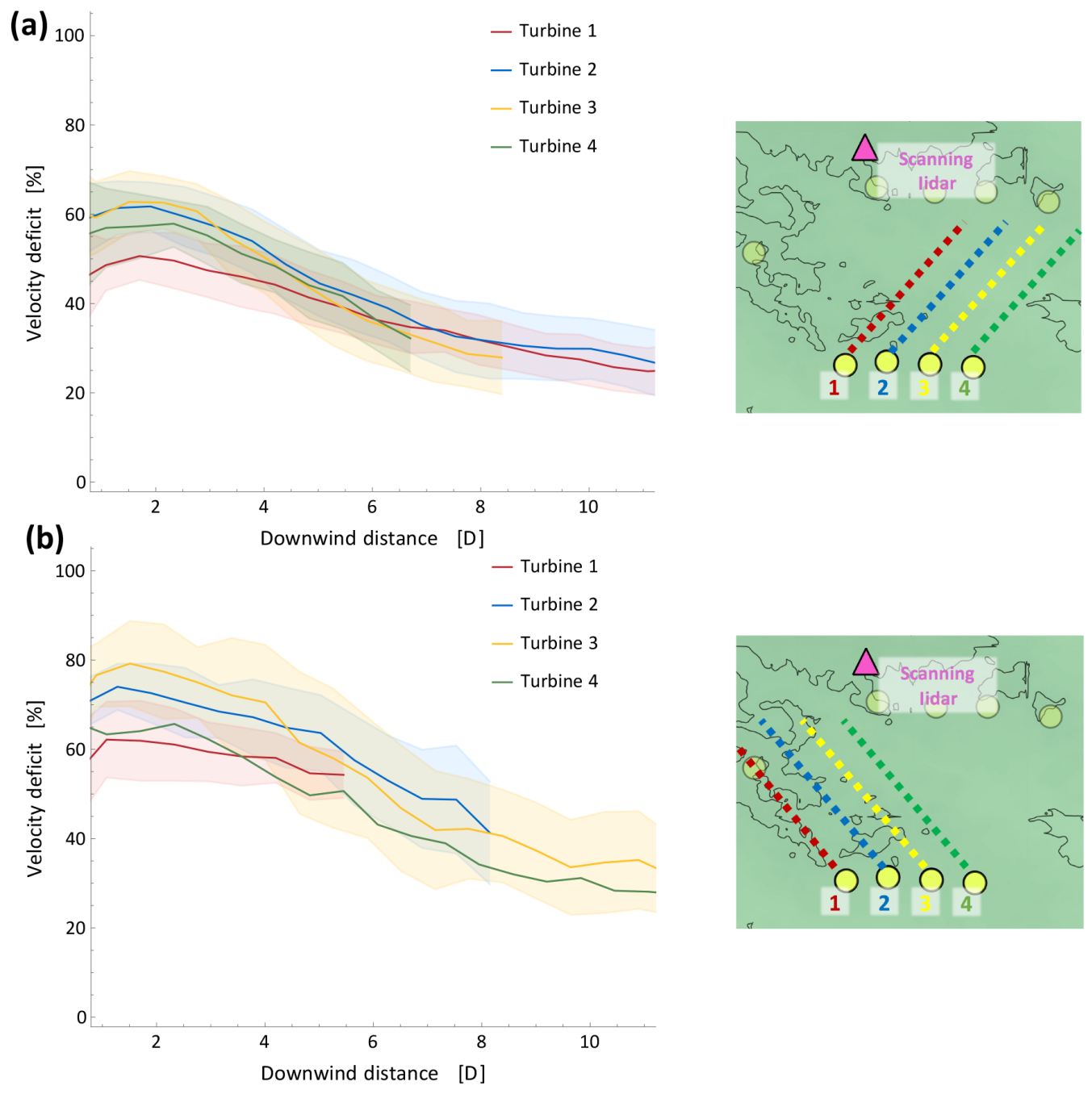

Figure 8. Velocity deficit vs. downwind distance, for the four wakes of the studied row of turbines. Continuous lines represent the median values calculated from the PPI scans performed at all the considered elevation angles during the night (stable conditions) of 26 (a) and 23 (b) August 2013; shaded areas show \pm 1 standard deviation of the data.

due to the high azimuthal resolution in each pencil-shaped area (panel a). However, if the wind direction - and thus the wake - is not aligned with the line of sight from the lidar (panel b), then the same wake will be measured as generally wider, since the retrieval of the wake width is now affected by the relatively coarse radial resolution of the lidar coordinate grid. In the schematic diagram shown in Fig. 10, at an arbitrary fixed downwind distance from the turbine, the (same) wake would be detected as $19 \%$ larger when it is not aligned with the line of sight from the scanning lidar. This result becomes more evident when the laser beam is more perpendicular to the wake. This result is due to the aspect ratio of the lidar "pixels" and thus would affect other wake characterization approaches relying on instruments not co-located with the turbine - such as in Banta et al. (2015) and Aitken et al. (2014a) - but would not affect nacelle-mounted wake measurements, such as in Bingöl et al. (2010) and Aitken and
Lundquist (2014), as nacelle-mounted wake measurements are usually aligned with the wake unless the wake is intentionally yawed (Fleming et al., 2016; Trujillo et al., 2016).

\subsection{Wake centerline results}

PPI scans at multiple elevation angles provide insight into the three-dimensional structure of wind turbine wakes. Different conditions at different vertical levels have a considerable impact on the wake centerline, i.e., the change of the position of the wake center downwind of the turbine.

Figure 11 shows a plot of the median position of the centers for the wakes of the two turbines located at the west edge of the considered row of four turbines for the 02:30 03:30 UTC (21:30-22:30 LDT) time period during the night of 26 August 2013 (southwesterly wind, panel a) and for the two turbines located at the east edge of the considered row of 
(a)
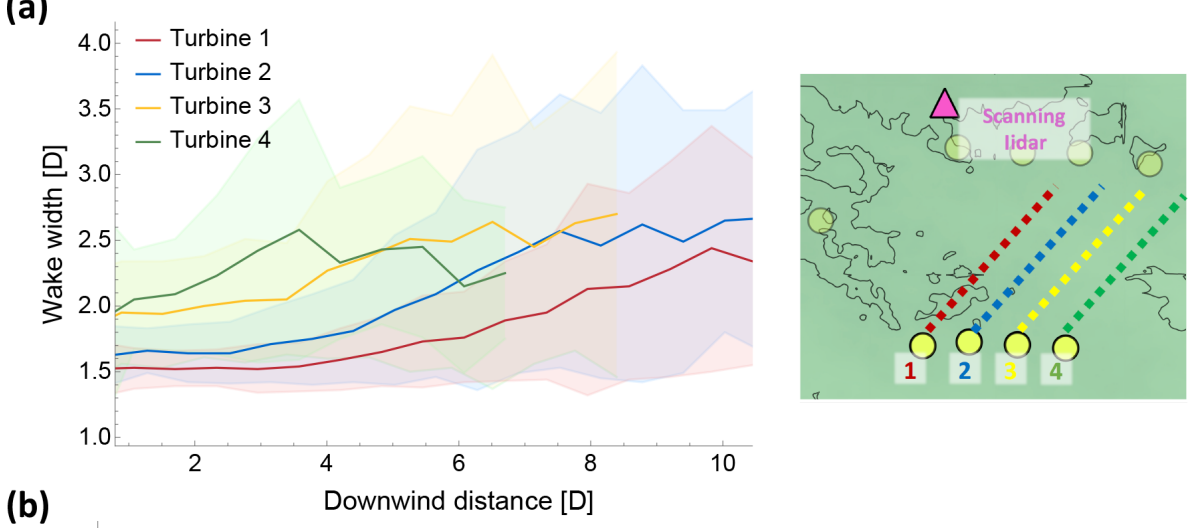

(b)
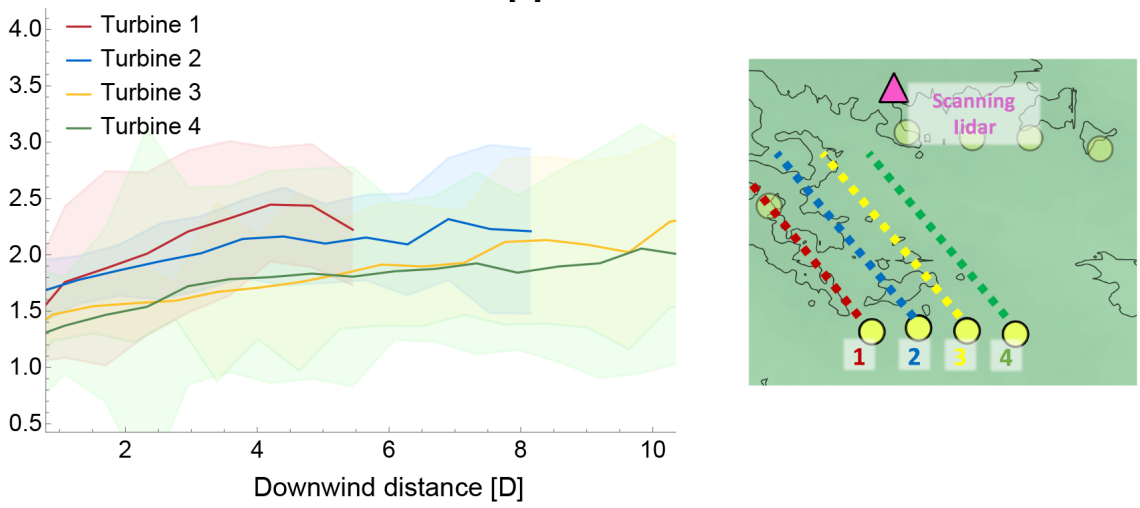

(c)
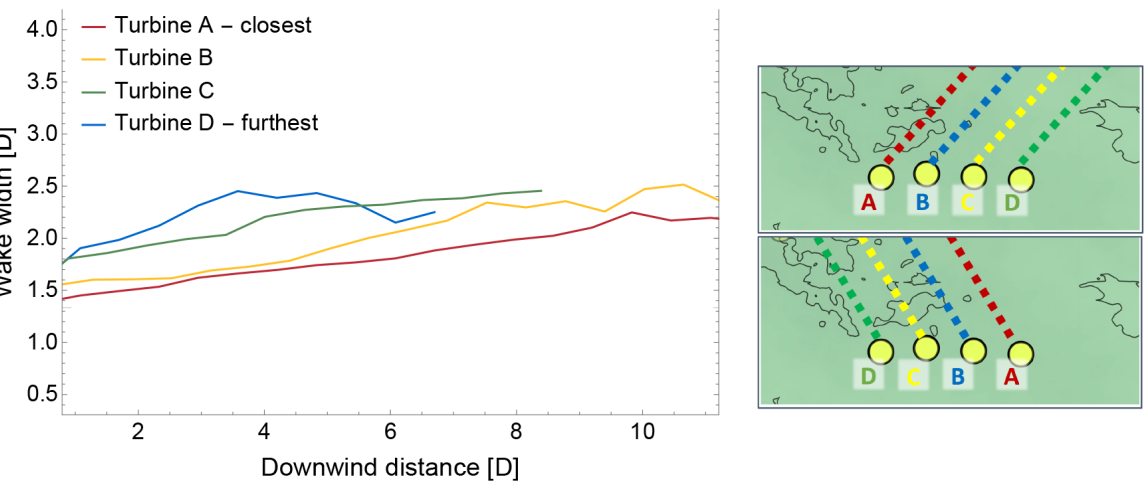

Figure 9. Wake width vs. downwind distance from the turbines, for the wakes of the four turbines in the studied row, from PPI scans performed at all the six considered elevation angles. Continuous lines represent median values; shaded areas show \pm 1 standard deviation of the data. (a) Data from the night (stable conditions) of 26 August 2013, with southwesterly wind conditions. (b) Data from the night (stable conditions) of 23 August 2013, with southeasterly wind conditions. (c) Aggregated plot, average of data from the nights of 26 and 23 August, considering the single turbines with reference to their relative distance from the scanning lidar.

four turbines for the 09:30-10:30 UTC (04:30-05:30 LDT) time period during the night of 23 August 2013 (southeasterly wind, panel b). Dashed lines represent the median value for the wake centerlines; continuous lines show the results for data points with different vertical heights: light colors show results for points with a vertical height between 35 and $55 \mathrm{~m}$, while dark colors refer to measurements taken above $75 \mathrm{~m}$ a.g.l. (these levels were chosen to create bins at low and high heights compared to the vertical dimension of the turbines, with approximately the same number of vertical posi- tions where the lidar measurements were taken, as shown in Fig. 2). A clear change in the position of the wake centers is detected between low and high vertical levels. This stretching is independent of wind direction: the change can be seen for both southwesterly (panel a, 26 August) and southeasterly (panel b, 23 August) wind conditions.

This change of the wake centerline with vertical height causes a stretching of the vertical structure of the wakes: the velocity deficit structure of a turbine wake, whose streamwise velocity deficit is traditionally considered as a 3-D 
(a)

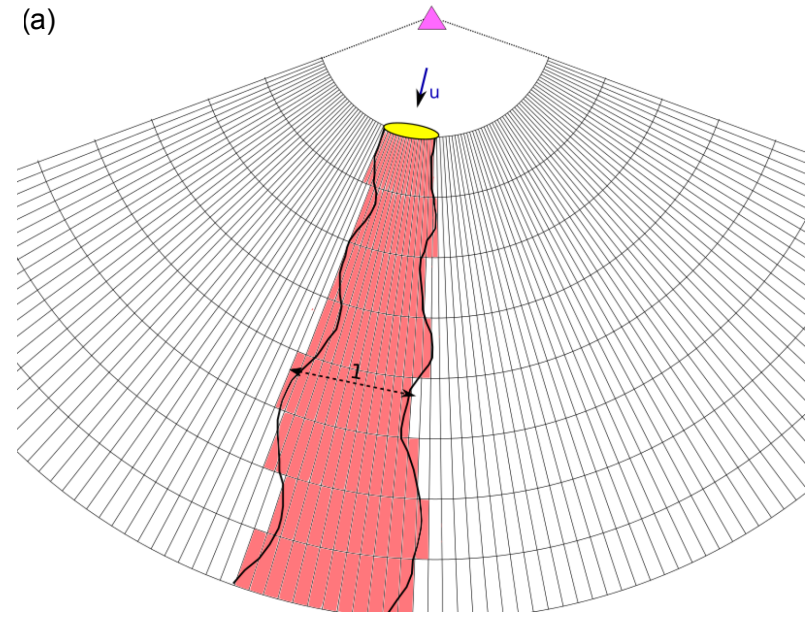

(b)

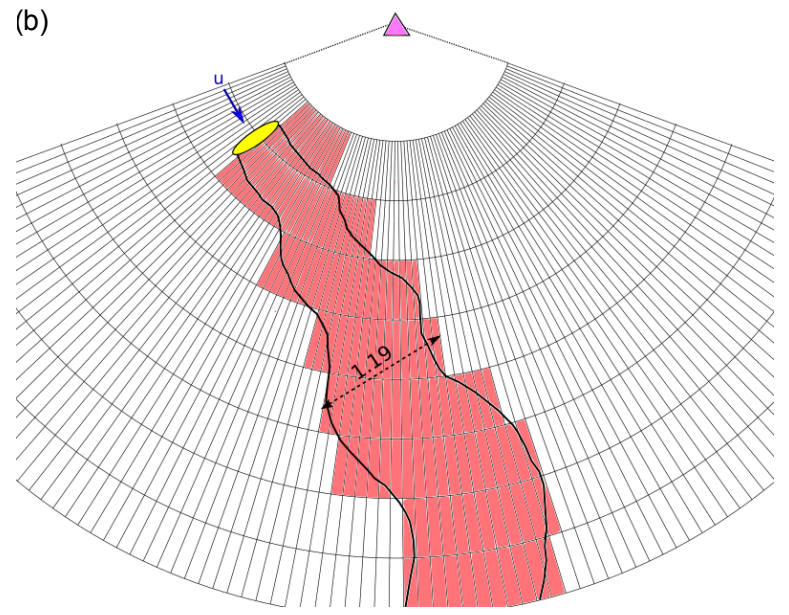

Figure 10. Qualitative sketch of the dependence of detected wake width on the orientation of the coordinate grid used by a scanning lidar (purple triangle) as a function of the wind direction. Panel (a) shows the case of a wake aligned with the line of sight from the scanning lidar (wind direction shown by the blue arrow), while panel (b) shows the case of a wake not aligned with the line of sight from the lidar. The dashed arrow highlights the difference in the detected wake width for the two cases, at fixed downwind distance from the turbine (yellow ellipse).

\section{(a)}
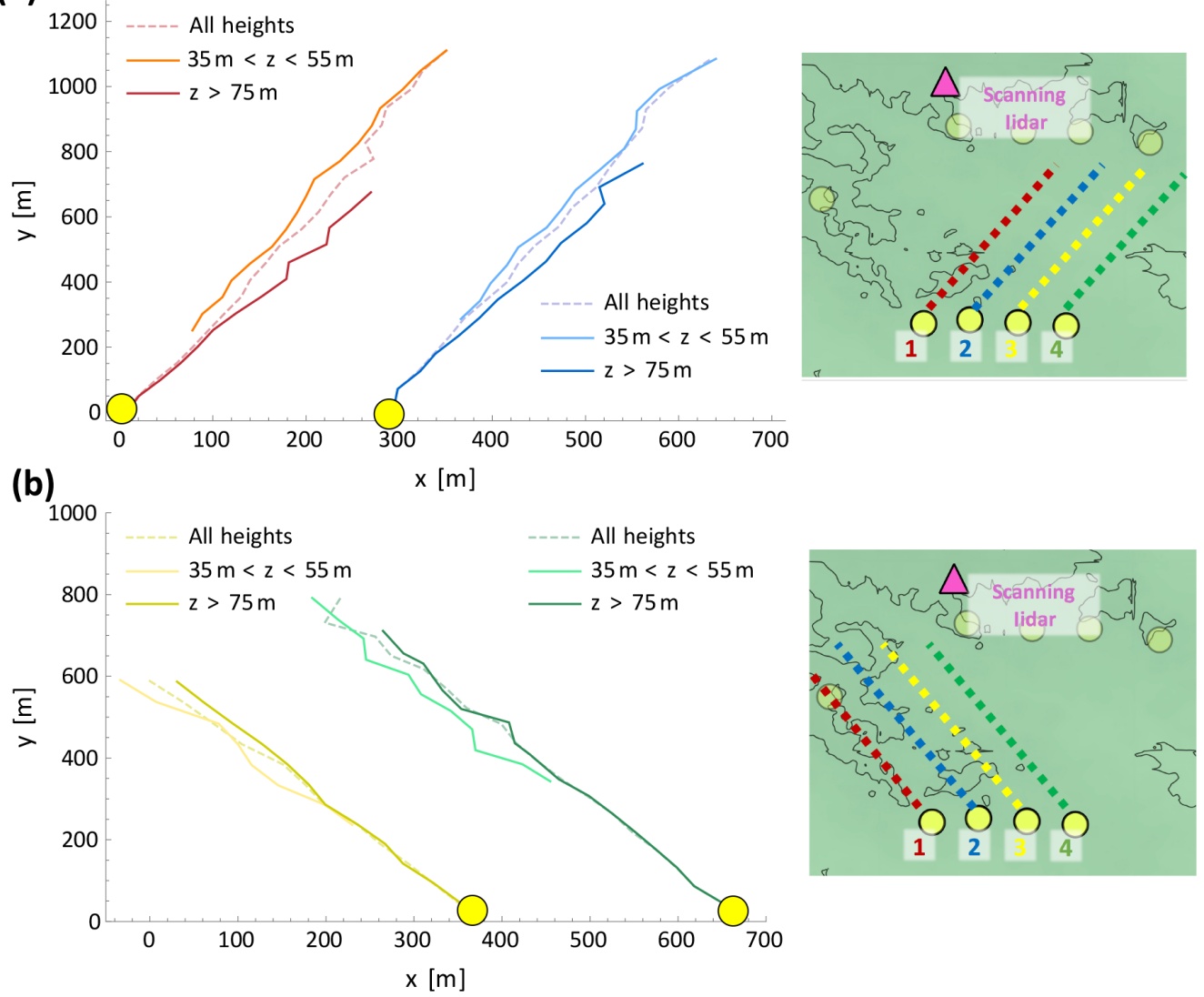

Figure 11. (a) Wake centerlines for an outer (on the left) and inner (on the right) turbine, from the PPI scans measurements during the 02:30-03:30 UTC (21:30-22:30 LDT) time period, 26 August 2013. (b) Wake centerlines for an inner (on the left) and outer (on the right) turbine; data from the 09:30-10:30 UTC (04:30-05:30 LDT) time period, 23 August 2013. Dashed lines represent the median values of wake centerlines, while the continuous lines show results at different vertical levels: for each wake, light colors refer to measurements between $35 \mathrm{~m}$ and $55 \mathrm{~m}$ a.g.l., while darker colors represent data points with a vertical height greater than $75 \mathrm{~m}$. Yellow dots show the position of wind turbines. 
(a)

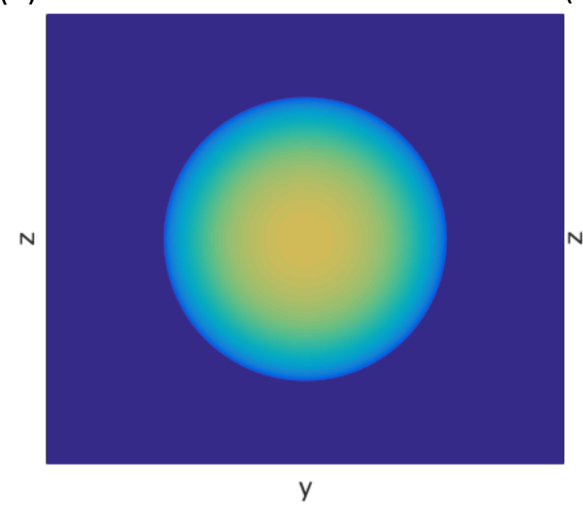

(b)

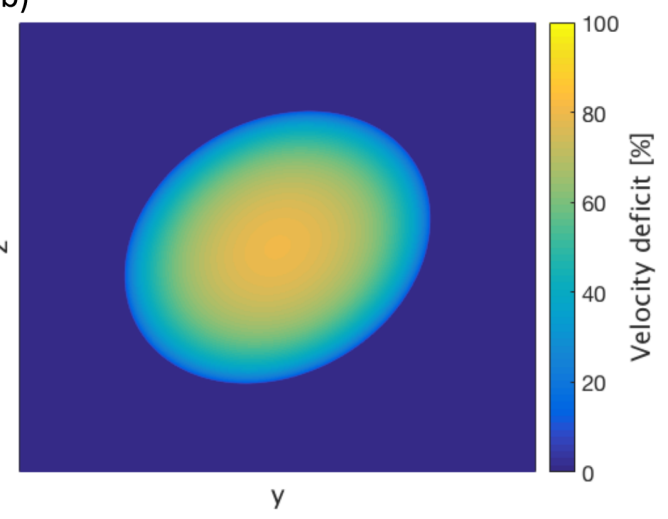

Figure 12. Qualitative cross-stream slices of stream-wise velocity deficit. The perspective is looking downwind. (a) A graphic representation of the classical Gaussian shape of the magnitude of wake velocity deficit. (b) An ellipsoid which represents the vertical stretching of the 3-D structure of a turbine wake as a consequence of wind veer.

Gaussian in a cross-stream plan (Fig. 12a), should instead be represented - when this vertical stretching occurs by a rotated ellipsoid (Fig. 12b), as already observed in both field measurements (Högström et al., 1988; Magnusson and Smedman, 1994) and large-eddy simulations (Lundquist et al., 2015; Vollmer et al., 2016).

\section{Relationship between ambient veer and wake centerline}

The vertical stretching of wake structure occurs because of the wind veer, the clockwise change of wind direction with height that often occurs in stable conditions, like those of 23 and 26 August 2013. To get a deeper insight on the relationship between ambient wind veer and vertical changes of the wake centerlines, we analyze several 30 min periods (each corresponding to two subsequent sequences of six PPI scans at the six different elevation angles) during the nights of 23 August 2013 (southeasterly wind) and 26 August 2013 (southwesterly wind). For each considered time frame, the wind veer is calculated as the average difference between the wind direction at 100 and $40 \mathrm{~m}$, as measured by the vertical profiling lidar located to measure upwind conditions (WC-1 in Fig. 1). The two vertical heights are chosen as representative of the two different vertical levels considered when assessing the changes of wake centerlines $(35 \mathrm{~m}<\mathrm{z}<55 \mathrm{~m}$ and $z>75 \mathrm{~m}$ ). Moreover, the wake centerlines at different vertical levels have been fitted with straight lines, and the angle between the lines which approximate the wake centerlines at $35 \mathrm{~m}<z<55 \mathrm{~m}$ and $z>75 \mathrm{~m}$ is calculated and then considered as the angular difference between the wake centerlines at different vertical levels. Figure 13 shows how angular difference between wake centerlines at different vertical levels compares to ambient wind veer between 100 and $40 \mathrm{~m}$, for all the available time frames during the nights of 23 and $26 \mathrm{Au}-$ gust 2013, for wakes from an inner and an outer turbine in the considered row.

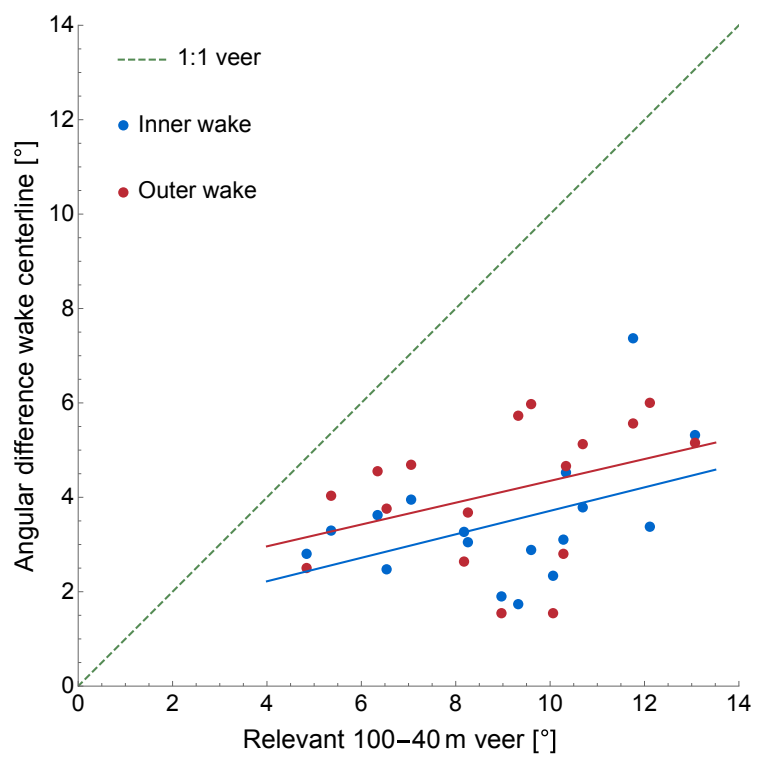

Figure 13. Angular difference between wake centerlines at different vertical heights $(35 \mathrm{~m}<z<55 \mathrm{~m}$ and $z>75 \mathrm{~m})$ vs. wind veer between 100 and $40 \mathrm{~m}$. Data for an inner and an outer wake in the considered row of four turbines, for several $30 \mathrm{~min}$ time frames during the nights of 23 and 26 August 2013. Continuous lines are the linear regressions from the data (red best fit: $2.04+0.23 x$; blue best fit: $1.23+0.25 x$ ), for the outer and the inner wake. Dashed line highlights the unreached equality between ambient veer and wake centerlines angular difference.

The results show that, although the angular change in the wake centerline at different vertical levels is systematically detected, the wind veer is always much larger than the actual angular difference between the wake centerlines at the different vertical levels: the change of the positions of the wake centers is related to, but not completely determined by, the wind veer. Moreover, as suggested by the linear regression 
fits, wakes from outer turbines often present a larger angular difference in wake centerlines compared to wakes from inner turbines, though with variability for different veer values that motivates further study.

A possible physical explanation for this phenomenon can be detected in the interaction between wake rotation due to rotating blades and wind veer. The blades of the wind turbines in CWEX-13 wind farm rotate clockwise and so the downwind wakes rotates counterclockwise (Burton et al., 2001). The wake can thus be considered as a sort of plume with its own momentum and rotation that interacts with the ambient veer, which in turn tends to rotate the wake in the opposite direction (in the Northern Hemisphere), thus causing a larger reduction in the global wake vertical stretching than would be present had only the ambient veer affected the wake. Inner wakes seem to be less subject to the effect of ambient wind veer, as if the presence of outer turbines reduces the ability of ambient wind characteristics to reach and impact inner regions of the wind farms.

\section{Conclusions}

Wakes from a row of four turbines have been characterized using line-of-sight wind speed measurements from PPI scans performed by a scanning lidar. Data were collected in late summer 2013 during the CWEX-13 field campaign (Lundquist et al., 2014), in a wind farm in a flat region in central Iowa. The wake characterization algorithm proposed by Aitken et al. (2014a) has been extended to assess wakes from multiple turbines.

Wakes erode quickly during unstable conditions of the atmosphere, and they can in fact be detected here primarily in stable conditions in this dataset. The velocity deficit in the wakes decreases with downwind distance from the turbines, and it is lower for wakes from outer turbines in the studied row. The width of the wakes increases with downwind distance, with systematic differences in the ability of the scanning lidar to detect the width of the wake according to the component of the direction the wakes perpendicular to the direction of laser beam of the scanning lidar. Wake centerlines change at different vertical levels as a consequence of the ambient wind veer, causing a stretching of the vertical structure of the wakes. Although the field measurements of Högström et al. (1988) and Magnusson and Smedman (1994) demonstrated that turbine wakes stretch into ellipses during stable conditions, for the first time we have quantified the effect of ambient wind veer on the stretching of wakes. In fact, the angular change in the wake centerlines at different heights is systematically much lower (a half or less) than the wind veer registered at the same heights. Moreover, this angular change of the wake centerlines at different vertical levels is found to be usually greater for wakes from outer turbines. This wake stretching, due to wind veer, not only is seen in these field measurements but also emerges in the stably stratified sim- ulations of Aitken et al. (2014b), Bhaganagar and Debnath (2015), Lundquist et al. (2015), Vollmer et al. (2016), and Abkar et al. (2016). As more three-dimensional measurements of wakes become available due to the use of scanning lidar and scanning radar, a more solid representation of wind turbine wakes can be assessed.

These results can become critically important to assess and improve large-eddy simulations of wakes as well as to suggest improvements to mesoscale parametrizations (Fitch et al., 2012, 2013; Jiménez et al., 2015; Lee and Lundquist, 2017) to account for subgrid-scale wake interactions. Moreover, wind energy companies can also benefit from our results in trying to enhance the quality of low-order wake models currently used for wind resource assessment, wind farm layout optimization, and wind farm control techniques, with the final goal of an improvement of wind energy production efficiency.

Code availability. The Matlab code of the wake characterization algorithm is publicly available at https://github.com/nicolabodini/ CWEX13 (Bodini, 2017).

Data availability. CWEX-13 data will be publicly available at the Dept. of Energy Atmosphere to electrons archive at https://a2e. energy.gov/projects.

\section{The Supplement related to this article is available online at https://doi.org/10.5194/amt-10-2881-2017-supplement.}

Competing interests. The authors declare that they have no conflict of interest.

Acknowledgements. This work was partially supported by the National Renewable Energy Laboratory under APUP UGA0-41026-22 and by the National Science Foundation grant BCS-1413980 (Coupled Human Natural Systems). Nicola Bodini was partially supported by a grant from the University of Trento for a visit to the University of Colorado Boulder in summer 2016.

Edited by: Mark Kulie

Reviewed by: Sandrine Aubrun, Nicolai Gayle Nygaard, and one anonymous referee

\section{References}

Abkar, M. and Porté-Agel, F.: Influence of atmospheric stability on wind-turbine wakes: A large-eddy simulation study, Phys. Fluids, 27, 035104, https://doi.org/10.1088/1742-6596/524/1/012138, 2015. 
Abkar, M., Sharifi, A., and Porté-Agel, F.: Large-eddy simulation of the diurnal variation of wake flows in a finite-size wind farm, J. Phys. Conf. Ser., 625, 012031, https://doi.org/10.1088/17426596/625/1/012031, 2015.

Abkar, M., Sharifi, A., and Porté-Agel, F.: Wake flow in a wind farm during a diurnal cycle, J. Turbul., 17, 420-441, https://doi.org/10.1080/14685248.2015.1127379, 2016.

Aitken, M. L. and Lundquist, J. K.: Utility-scale wind turbine wake characterization using nacelle-based long-range scanning lidar, J. Atmos. Ocean. Tech., 31, 1529-1539, https://doi.org/10.1175/JTECH-D-13-00218.1, 2014.

Aitken, M. L., Banta, R. M., Pichugina, Y. L., and Lundquist, J. K.: Quantifying wind turbine wake characteristics from scanning remote sensor data, J. Atmos. Ocean. Tech., 31, 765-787, https://doi.org/10.1175/JTECH-D-13-00104.1, 2014a.

Aitken, M. L., Kosović, B., Mirocha, J. D., and Lundquist, J. K.: Large eddy simulation of wind turbine wake dynamics in the stable boundary layer using the Weather Research and Forecasting Model, Journal of Renewable and Sustainable Energy, 6, 033137, https://doi.org/10.1063/1.4885111, 2014 b.

Andersen, S. J., Sørensen, J. N., Ivanell, S., and Mikkelsen, R. F.: Comparison of engineering wake models with CFD simulations, J. Phys. Conf. Ser., 524, 012161, https://doi.org/10.1088/17426596/524/1/012161, 2014.

Aubrun, S., Garcia, E. T., Boquet, M., Coupiac, O., and Girard, N.: Wind turbine wake tracking and its correlations with wind turbine monitoring sensors. Preliminary results, J. Phys. Conf. Ser., 753, 032003, https://doi.org/10.1088/1742-6596/753/3/032003, 2016.

Babić, K., Bencetić Klaić, Z., and Večenaj, Ž.: Determining a turbulence averaging time scale by Fourier analysis for the nocturnal boundary layer, Geofizika, 29, 35-51, 2012.

Banta, R. M., Pichugina, Y. L., Brewer, W. A., Lundquist, J. K., Kelley, N. D., Sandberg, S. P., Alvarez II, R. J., Hardesty, R. M., and Weickmann, A. M.: 3D volumetric analysis of wind turbine wake properties in the atmosphere using high-resolution Doppler lidar, J. Atmos. Ocean. Tech., 32, 904-914, 2015.

Barthelmie, R., Larsen, G., Frandsen, S., Folkerts, L., Rados, K., Pryor, S., Lange, B., and Schepers, G.: Comparison of wake model simulations with offshore wind turbine wake profiles measured by sodar, J. Atmos. Ocean. Tech., 23, 888-901, 2006.

Barthelmie, R. J., Pryor, S., Frandsen, S. T., Hansen, K. S., Schepers, J., Rados, K., Schlez, W., Neubert, A., Jensen, L., and Neckelmann, S.: Quantifying the impact of wind turbine wakes on power output at offshore wind farms, J. Atmos. Ocean. Tech., 27, 1302-1317, 2010.

Barthelmie, R. J., Hansen, K. S., and Pryor, S. C.: Meteorological controls on wind turbine wakes, P. IEEE, 101, 1010-1019, 2013.

Bastine, D., Wächter, M., Peinke, J., Trabucchi, D., and Kühn, M.: Characterizing Wake Turbulence with Staring Lidar Measurements, J. Phys. Conf. Ser., 625, 012006, https://doi.org/10.1088/1742-6596/625/1/012006, 2015.

Bhaganagar, K. and Debnath, M.: The effects of mean atmospheric forcings of the stable atmospheric boundary layer on wind turbine wake, Journal of Renewable and Sustainable Energy, 7, 013124, https://doi.org/10.1063/1.4907687, 2015.

Bingöl, F., Mann, J., and Larsen, G. C.: Light detection and ranging measurements of wake dynamics part I: one-dimensional scan- ning, Wind Energy, 13, 51-61, https://doi.org/10.1002/we.352, 2010.

Bodini, N.: Multiple-wake detection algorithm for CWEX-13, University of Colorado Boulder, available at: https://github.com/ nicolabodini/CWEX13, last access: 9 August 2017.

Brower, M.: Wind resource assessment: a practical guide to developing a wind project, John Wiley \& Sons, Hoboken, New Jersey, USA, https://doi.org/10.1002/9781118249864, 2012.

Burton, T., Sharpe, D., Jenkins, N., and Bossanyi, E.: Wind energy handbook, John Wiley \& Sons, Hoboken, New Jersey, USA, https://doi.org/10.1002/9781119992714, 2001.

Cariou, J.-P., Sauvage, L., Thobois, L., Gorju, G., Machta, M., Lea, G., and Duboué, M.: Long range scanning pulsed Coherent Lidar for real time wind monitoring in the Planetary Boundary Layer, in: 16th Coherent Laser Radar Conference, 20-24 June 2011, Long Beach, California, USA, 148-152, 2011.

Chamorro, L. P. and Porté-Agel, F.: A Wind-Tunnel Investigation of Wind-Turbine Wakes: Boundary-Layer Turbulence Effects, Bound.-Lay. Meteorol., 132, 129-149, https://doi.org/10.1007/s10546-009-9380-8, 2009.

Chowdhury, S., Zhang, J., Messac, A., and Castillo, L.: Unrestricted wind farm layout optimization (UWFLO): Investigating key factors influencing the maximum power generation, Renew. Energ., 38, 16-30, 2012.

Churchfield, M. J., Lee, S., Michalakes, J., and Moriarty, P. J.: A numerical study of the effects of atmospheric and wake turbulence on wind turbine dynamics, J. Turbul., 13, N14, https://doi.org/10.1080/14685248.2012.668191, 2012.

Clifton, A., Smith, A., and Fields, M.: Wind Plant Preconstruction Energy Estimates: Current Practice and Opportunities, Tech. rep., NREL (National Renewable Energy Laboratory (NREL), Golden, CO, USA), available at: http://www.nrel.gov/ docs/fy16osti/64735.pdf (last access: 9 August 2017), 2016.

Clive, P. J., Dinwoodie, I., and Quail, F.: Direct measurement of wind turbine wakes using remote sensing, Proc. EWEA 2011, available at: http://www.sgurrenergy.com/wp/wpcontent/uploads/2016/05/Industry-paper-Direct-measurementof-wind-turbine-wakes-using-remote-sensing.pdf (last access: 9 August 2017), 2011.

Crespo, A., Hernandez, J., and Frandsen, S.: Survey of modelling methods for wind turbine wakes and wind farms, Wind energy, 2, 1-24, 1999.

Debnath, M., Iungo, G. V., Brewer, W. A., Choukulkar, A., Delgado, R., Gunter, S., Lundquist, J. K., Schroeder, J. L., Wilczak, J. M., and Wolfe, D.: Assessment of virtual towers performed with scanning wind lidars and Ka-band radars during the XPIA experiment, Atmos. Meas. Tech., 10, 1215-1227, https://doi.org/10.5194/amt-10-1215-2017, 2017.

De Franceschi, M. and Zardi, D.: Evaluation of cut-off frequency and correction of filter-induced phase lag and attenuation in eddy covariance analysis of turbulence data, Bound.-Lay. Meteorol., 108, 289-303, 2003.

De Franceschi, M., Zardi, D., Tagliazucca, M., and Tampieri, F.: Analysis of second-order moments in surface layer turbulence in an Alpine valley, Q. J. Roy. Meteor. Soc., 135, 1750-1765, 2009.

Dörenkämper, M., Witha, B., Steinfeld, G., Heinemann, D., and Kühn, M.: The impact of stable atmospheric boundary layers on wind-turbine wakes within offshore 
wind farms, J. Wind Eng. Ind. Aerod., 144, 146-153, https://doi.org/10.1016/j.jweia.2014.12.011, 2015.

Elkinton, C. N., Manwell, J. F., and McGowan, J. G.: Offshore wind farm layout optimization (OWFLO) project: Preliminary results, University of Massachusetts, https://doi.org/10.2514/6.2006998, 2006

Fitch, A. C., Olson, J. B., Lundquist, J. K., Dudhia, J., Gupta, A. K., Michalakes, J., and Barstad, I.: Local and Mesoscale Impacts of Wind Farms as Parameterized in a Mesoscale NWP Model, Mon. Weather Rev., 140, 3017-3038, https://doi.org/10.1175/MWRD-11-00352.1, 2012

Fitch, A. C., Olson, J. B., and Lundquist, J. K.: Parameterization of Wind Farms in Climate Models, J. Climate, 26, 6439-6458, https://doi.org/10.1175/JCLI-D-12-00376.1, 2013.

Fleming, P. A., Gebraad, P. M., Lee, S., van Wingerden, J.-W., Johnson, K., Churchfield, M., Michalakes, J., Spalart, P., and Moriarty, P.: Evaluating techniques for redirecting turbine wakes using SOWFA, Renew. Energ., 70, 211-218, 2014.

Fleming, P. A., Ning, A., Gebraad, P. M. O., and Dykes, K.: Wind plant system engineering through optimization of layout and yaw control, Wind Energy, 19, 329-344, https://doi.org/10.1002/we.1836, 2016.

Gaumond, M., Réthoré, P.-E., Ott, S., Pena, A., Bechmann, A., and Hansen, K. S.: Evaluation of the wind direction uncertainty and its impact on wake modeling at the Horns Rev offshore wind farm, Wind Energy, 17, 1169-1178, 2014.

Gebraad, P., Teeuwisse, F., Wingerden, J., Fleming, P. A., Ruben, S., Marden, J., and Pao, L.: Wind plant power optimization through yaw control using a parametric model for wake effects - a CFD simulation study, Wind Energy, 19, 95-114, 2016.

Hansen, K. S., Barthelmie, R. J., Jensen, L. E., and Sommer, A.: The impact of turbulence intensity and atmospheric stability on power deficits due to wind turbine wakes at Horns Rev wind farm, Wind Energy, 15, 183-196, 2012.

Hirth, B. D. and Schroeder, J. L.: Documenting Wind Speed and Power Deficits behind a Utility-Scale Wind Turbine, J. Appl. Meteorol. Clim., 52, 39-46, https://doi.org/10.1175/JAMC-D12-0145.1, 2013.

Hirth, B. D., Schroeder, J. L., Gunter, W. S., and Guynes, J. G.: Measuring a utility-scale turbine wake using the TTUKa mobile research radars, J. Atmos. Ocean. Tech., 29, 765-771, 2012.

Hirth, B. D., Schroeder, J. L., Gunter, W. S., and Guynes, J. G.: Coupling Doppler radar-derived wind maps with operational turbine data to document wind farm complex flows, Wind Energy, 18, 529-540, 2015a.

Hirth, B. D., Schroeder, J. L., Irons, Z., and Walter, K.: Dual-Doppler measurements of a wind ramp event at an Oklahoma wind plant, Wind Energy, 19, 953-962, https://doi.org/10.1002/we.1867, 2015b.

Högström, U., Asimakopoulos, D., Kambezidis, H., Helmis, C., and Smedman, A.: A field study of the wake behind a $2 \mathrm{MW}$ wind turbine, Atmos. Environ., 22, 803-820, 1988.

Iungo, G. V., Wu, Y.-T., and Porté-Agel, F.: Field Measurements of Wind Turbine Wakes with Lidars, J. Atmos. Ocean. Tech., 30, 274-287, https://doi.org/10.1175/JTECH-D-12-00051.1, 2013.

Jensen, N. O.: A note on wind generator interaction, available at: http://orbit.dtu.dk/fedora/objects/orbit:88807/datastreams/file_ 3494b4b2-1dae-4442-941a-f2e628673f31/content (last access: 9 August 2017), 1983
Jiménez, P. A., Navarro, J., Palomares, A. M., and Dudhia, J.: Mesoscale modeling of offshore wind turbine wakes at the wind farm resolving scale: a composite-based analysis with the Weather Research and Forecasting model over Horns Rev, Wind Energy, 18, 559-566, https://doi.org/10.1002/we.1708, 2015.

Käsler, Y., Rahm, S., Simmet, R., and Kühn, M.: Wake measurements of a multi-MW wind turbine with coherent long-range pulsed Doppler wind lidar, J. Atmos. Ocean. Tech., 27, 15291532, 2010.

Katic, I., Højstrup, J., and Jensen, N. O.: A simple model for cluster efficiency, in: European Wind Energy Association Conference and Exhibition, 7-9 October 1986, Rome, Italy, 407-410, 1986.

Kleinbaum, D. G., Kupper, L. L., Nizam, A., and Rosenberg, E. S.: Applied regression analysis and other multivariable methods, Nelson Education, Scarborough, Canada, 2013.

Kumer, V.-M., Reuder, J., Svardal, B., Sætre, C., and Eecen, P.: Characterisation of single wind turbine wakes with static and scanning WINTWEX-W LiDAR data, Energy Procedia, 80, 245-254, 2015.

Landberg, L.: Meteorology for Wind Energy: An Introduction, John Wiley \& Sons, Hoboken, New Jersey, USA, 2015.

Lee, J. C.-Y. and Lundquist, J.: Observing and Simulating Wind Turbine Wakes during the Evening Transition, Bound.-Lay. Meteorol., 164, 449-474, https://doi.org/10.1007/s10546-017-0257y, 2017.

Lundquist, J. K., Takle, E. S., Boquet, M., Kosović, B., Rhodes, M. E., Rajewski, D., Doorenbos, R., Irvin, S., Aitken, M. L., Friedrich, K., Quelet, P. T., Rana, J., St. Martin, C., Vanderwende, B., and Worsnop, R.: Lidar observations of interacting wind turbine wakes in an onshore wind farm, in: EWEA meeting proceedings, 10-13 March 2014, Barcelona, Spain, 2014.

Lundquist, J. K., Churchfield, M. J., Lee, S., and Clifton, A.: Quantifying error of lidar and sodar Doppler beam swinging measurements of wind turbine wakes using computational fluid dynamics, Atmos. Meas. Tech., 8, 907-920, https://doi.org/10.5194/amt-8-907-2015, 2015.

Machefaux, E., Larsen, G. C., Koblitz, T., Troldborg, N., Kelly, M. C., Chougule, A., Hansen, K. S., and Rodrigo, J. S.: An experimental and numerical study of the atmospheric stability impact on wind turbine wakes, Wind Energy, 19, 1785-1805, https://doi.org/10.1002/we.1950, 2015.

Magnusson, M.: Near-wake behaviour of wind turbines, J. Wind Eng. Ind. Aerod., 80, 147-167, 1999.

Magnusson, M. and Smedman, A.: Influence of atmospheric stability on wind turbine wakes, Wind Engineering, 18, 139-152, 1994.

Mirocha, J. D., Kosovic, B., Aitken, M. L., and Lundquist, J. K.: Implementation of a generalized actuator disk wind turbine model into the weather research and forecasting model for large-eddy simulation applications, Journal of Renewable and Sustainable Energy, 6, 013104, https://doi.org/10.1063/1.4861061, 2014.

Mirocha, J. D., Rajewski, D. A., Marjanovic, N., Lundquist, J. K., Kosović, B., Draxl, C., and Churchfield, M. J.: Investigating wind turbine impacts on near-wake flow using profiling lidar data and large-eddy simulations with an actuator disk model, Journal of Renewable and Sustainable Energy, 7, 043143 , https://doi.org/10.1063/1.4928873, 2015.

Muñoz-Esparza, D., Cañadillas, B., Neumann, T., and van Beeck, J.: Turbulent fluxes, stability and shear in the offshore environ- 
ment: Mesoscale modelling and field observations at FINO1, Journal of Renewable and Sustainable Energy, 4, 063136, https://doi.org/10.1063/1.4769201, 2012.

Neustadter, H. and Spera, D.: Method for evaluating wind turbine wake effects on wind farm performance, J. Sol. Energ.-T. ASME, 107, 240-243, https://doi.org/10.1115/1.3267685, 1985.

Nygaard, N. G.: Wakes in very large wind farms and the effect of neighbouring wind farms, J. Phys. Conf. Ser., 524, 012162 , https://doi.org/10.1088/1742-6596/524/1/012162, 2014.

Rajewski, D. A., Takle, E. S., Lundquist, J. K., Oncley, S., Prueger, J. H., Horst, T. W., Rhodes, M. E., Pfeiffer, R., Hatfield, J. L., Spoth, K. K., and Doorenbos, R. K.: CROP WIND ENERGY EXPERIMENT (CWEX): Observations of SurfaceLayer, Boundary Layer, and Mesoscale Interactions with a Wind Farm, B. Am. Meteorol. Soc., 94, 655-672, 2013.

Rhodes, M. E. and Lundquist, J. K.: The Effect of Wind-Turbine Wakes on Summertime US Midwest Atmospheric Wind Profiles as Observed with Ground-Based Doppler Lidar, Bound.Lay. Meteorol., 149, 85-103, https://doi.org/10.1007/s10546013-9834-x, 2013.

Samorani, M.: The wind farm layout optimization problem, in: Handbook of Wind Power Systems, Springer, Berlin, Germany, 21-38, 2013.

Sathe, A. and Mann, J.: A review of turbulence measurements using ground-based wind lidars, Atmos. Meas. Tech., 6, 3147-3167, https://doi.org/10.5194/amt-6-3147-2013, 2013.

Sathe, A., Mann, J., Barlas, T., Bierbooms, W., and van Bussel, G.: Influence of atmospheric stability on wind turbine loads: Atmospheric stability and loads, Wind Energy, 16, 1013-1032, https://doi.org/10.1002/we.1528, 2013.

Takle, E. S., Rajewski, D. A., Lundquist, J. K., Gallus, W. A., and Sharma, A.: Measurements in support of wind farm simulations and power forecasts: The Crop/Wind-energy Experiments (CWEX), J. Phys. Conf. Ser., 524, 012174, https://doi.org/10.1088/1742-6596/524/1/012174, 2014.

Tennekes, H. and Lumley, J. L.: A first course in turbulence, MIT press, Cambridge, MA, USA, 1972.
Troldborg, N., Sørensen, J. N., and Mikkelsen, R.: Actuator line simulation of wake of wind turbine operating in turbulent inflow, J. Phys. Conf. Ser., 75, 012063, https://doi.org/10.1088/17426596/75/1/012063, 2007.

Trujillo, J.-J., Bingöl, F., Larsen, G. C., Mann, J., and Kühn, M.: Light detection and ranging measurements of wake dynamics. Part II: two-dimensional scanning, Wind Energy, 14, 61-75, 2011.

Trujillo, J. J., Seifert, J. K., Würth, I., Schlipf, D., and Kühn, M.: Full-field assessment of wind turbine near-wake deviation in relation to yaw misalignment, Wind Energ. Sci., 1, 41-53, https://doi.org/10.5194/wes-1-41-2016, 2016.

Vanderwende, B. J. and Lundquist, J. K.: The modification of wind turbine performance by statistically distinct atmospheric regimes, Environ. Res. Lett., 7, 034035, https://doi.org/10.1088/1748-9326/7/3/034035, 2012.

Vanderwende, B. J., Lundquist, J. K., Rhodes, M. E., Takle, E. S., and Irvin, S. L.: Observing and Simulating the Summertime Low-Level Jet in Central Iowa, Mon. Weather Rev., 143, 23192336, https://doi.org/10.1175/MWR-D-14-00325.1, 2015.

van Dooren, M. F., Trabucchi, D., and Kühn, M.: A Methodology for the Reconstruction of 2D Horizontal Wind Fields of Wind Turbine Wakes Based on Dual-Doppler Lidar Measurements, Remote Sensing, 8, 809, https://doi.org/10.3390/rs8100809, 2016.

Vermeer, L., Sørensen, J. N., and Crespo, A.: Wind turbine wake aerodynamics, Prog. Aerosp. Sci., 39, 467-510, 2003.

Vollmer, L., Steinfeld, G., Heinemann, D., and Kühn, M.: Estimating the wake deflection downstream of a wind turbine in different atmospheric stabilities: an LES study, Wind Energ. Sci., 1, 129141, https://doi.org/10.5194/wes-1-129-2016, 2016.

Wang, H. and Barthelmie, R.: Wind turbine wake detection with a single Doppler wind lidar, J. Phys. Conf. Ser., 625, 012017 https://doi.org/10.1088/1742-6596/625/1/012017, 2015.

Wharton, S. and Lundquist, J. K.: Atmospheric stability affects wind turbine power collection, Environ. Res. Lett., 7, 014005, https://doi.org/10.1088/1748-9326/7/1/014005, 2012. 